\title{
África: o outro vértice do triângulo
}

\author{
António T. Marques \\ Faculdade de Ciências do Desporto e de Educação Física, Universidade do Porto
}

https://doi.org/10.5628/rpcd.01.01.23

\section{PREÂMBULO}

O texto que a seguir se apresenta constituiu a lição proferida durante a cerimónia de atribuição do Grau de Doutor Honoris Causa pela Universidade Pedagógica de Moçambique em 5 de Novembro de 1997.

Dissemos na altura, e reafirmamo-lo agora, que este acto constituiu o reconhecimento público pela Universidade Moçambicana do contributo que a nossa Faculdade tem vindo a prestar à cooperação com Moçambique.

Não seria justificado aqui o enunciado fastidioso do que tem sido a nossa cooperação com África e em particular com a Faculdade de Ciências da Educação Física e Desporto da Universidade Pedagógica de Moçambique nos últimos 15 anos. Brevemente, numa iniciativa conjunta das duas Faculdades com a colaboração do Centro de Estudos e Formação Desportiva do Instituto Nacional dos Desportos, dará à estampa um extenso volume que apresentará de forma mais circunstanciada os resultados da cooperação.

Tendo a actualidade que se perceberá, a lição que então proferimos permitirá conhecer melhor os contornos da política de cooperação da nossa Faculdade com África que, no caso de Moçambique, tem sido considerada um exemplo a seguir noutros países africanos.

Resta dizer que a cooperação só é possível quando há interesse e empenhamento de das partes. Nunca a nossa Faculdade teria levado tão longe a cooperação sem a coesão de uma escola em torno de um projecto animado pelo Doutor António Manuel Prista e Silva, verdadeira alma mater da Faculdade nossa parceira neste projecto.

\section{Sr. Reitor}

Sr. Ministro da Educação

Sr. Ministro da Cultura, Juventude e Desportos

Sr. Embaixador de Portugal

Colegas

Minhas senhoras e meus senhores

Quero começar por agradecer à Universidade Pedagógica de Moçambique tão elevada distinção. Entendo-a como um tributo a um singelo mas empenhado esforço de cooperação que a minha Faculdade e os meus companheiros vêm fazendo no apoio à jovem Faculdade de Ciências da Educação Física e Desporto deste país.

De acordo com a tradição académica deve o homenageado proferir uma lição. É isso que procurarei fazer, elegendo como tema da minha exposição a cooperação universitária entre países desenvolvidos e países em desenvolvimento. É ainda neste contexto que procurarei situar alguns problemas da Educação Física e do Desporto.

\section{LIMITES E CONTORNOS DA COOPERAÇÃO UNIVERSITÁRIA}

A cooperação tem sido objecto das minhas preocupações ao longo de quase toda a minha vida académica. Interesse que saiu reforçado durante os oito anos em que assumi funções de director na Faculdade a que pertenço.

Foi neste quadro que lançámos, perfazem-se agora dez anos, conjuntamente com o Doutor Jorge Bento e os Doutores Alfredo Faria Júnior e Roberto Ferreira dos Santos da Universidade do Estado do Rio de Janeiro, as bases de um importante projecto: um movimento de cooperação entre as universidades 
e escolas de educação física e desporto dos países de expressão portuguesa. Projecto que encontra a sua manifestação mais visível na realização do Congresso de Educação Física dos Países de Língua Portuguesa, que este ano teve lugar nesta cidade de Maputo. Um congresso que, agora em $6^{\mathrm{a}}$ edição, tem vindo a promover um desígnio: aproximar pessoas e instituições que têm no centro das suas preocupações o estudo do Desporto e da Educação Física, afirmando uma comunidade científica no espaço de uma língua comum - a língua portuguesa. (1)

Uma língua que dá voz a comunidades nas sete partidas do mundo. Constituindo-se como veículo de comunicação entre um dos grupos populacionais mais numerosos do planeta, de que Angola, Brasil, Cabo Verde, Guiné, Moçambique, Portugal, São Tomé e Príncipe são apenas os contornos mais visíveis. Uma língua de superação das barreiras da incompreensão, de abertura de um grande e vivo espaço de diálogo, de cooperação, de fraternidade. Como dizia uma figura insigne da minha universidade, o Professor Nuno Grande, a propósito do $2^{\circ}$ Congresso de Educação Física dos Países de Língua Portuguesa realizado na cidade do Porto em 1991: "Percorremos juntos largos períodos da História, vivendo momentos de glória e de exaltação dos valores da civilização; sofremos também a amargura das imposições das forças retrógradas, que tentaram cavar entre nós os fossos de incompreensão e do ódio. Sinto que aos universitários compete o papel de ultrapassar as incompreensões e os diferendos tornando possível o diálogo aberto entre todos os que têm a responsabilidade de conduzir os destinos dos povos."

Este é também o sentido substantivo das nossas motivações, no que constitui um desafio exaltante, estimulante, mobilizador. Melhor interpretado pelo reitor da Universidade do Porto, o Professor Alberto Amaral, que tem vindo nos últimos anos a desenvolver um grande esforço de internacionalização da universidade, num estreito comprometimento com os princípios da Magna Carta das Universidades Europeias: "Depositária da tradição do humanismo europeu, mas com a preocupação constante de alcançar o saber universal, a Universidade, para assumir as suas missões, ignora as fronteiras geográficas ou políticas e afirma a necessidade imperiosa do conhecimento recíproco e da interacção de culturas".

E se o empenhamento na internacionalização transcende, em muito, o espaço da língua portuguesa, na realização deste desígnio é notória uma clara e determinada aposta nas relações com os jovens países africanos de língua portuguesa.

Sem quaisquer intuitos neo-colonizadores, assim o cremos. E também sem quaisquer complexos de colonizados, assim se espera. É imperativa a necessidade de consciencialização de uma nova atitude, volvidos os anos de maiores dificuldades e de incompreensão recíprocos. Torna-se necessário superar "as marcas de um passado de colonização envergonhada, a pequenez política, os entraves financeiros e os jogos de influência..." (10, pg. 37) que têm prejudicado gravemente as relações entre os nossos povos.

Compreendemos Mia Couto quando diz que as coisas não estão resolvidas. Que não chegamos ainda a uma relação amigável e franca. Que ainda não percebemos Moçambique.

Os próprios moçambicanos não terão ainda entendido "os mundos diferentes que compõem Moçambique", a que Mia chama "um país sem imagem." (9) Mas devemos esforçar-nos para que isso possa acontecer. E possa acontecer, como diz Craveirinha, Prémio Camões em 1991 e, no dizer de Samora Machel, o grande poeta nacional de Moçambique, "sem desvalorizar o conquistado por séculos de convívio". Antes emprestando a este novo relacionamento novos contornos no sentido de uma aceitação mútua. (9)

Saibamos superar, de vez, estas barreiras e compreender melhor os novos contornos da história. Sem ignorarmos ou esquecermos - uma vez mais Mia Couto - que "falar em cultura comum é já um disparate" e que mesmo para a língua, criamos "miolos" diferentes. (9)

A relação histórica de Portugal com povos de todos os continentes determinou possibilidades de diálogo entre culturas muito diferentes e ricas. Essa comunicação faz-se na língua portuguesa, uma língua pluricontinental, multiétnica, multicultural e plurireligiosa, que se constitui como um instrumento privilegiado de diálogo.

Este o sentido maior de possuirmos uma língua 
comum. Uma língua dinâmica, moldável, enriquecida com os "miolos" que cada povo lhe vai acrescentando e que nos permitirá estabelecer os contornos de uma nova e diferente relação.

Estamos na cooperação para cooperar, perdoem-nos a redundância. Desde o seu início, o nosso envolvimento na cooperação foi não apenas solicitado, mas concertado nos mais pequenos detalhes com quem o solicitou.

É claro que essa solicitação foi feita num contexto de conhecimento recíproco, em relações académicas anteriormente estabelecidas.

É claro ainda, e aqui o afirmamos, que acreditamos na diversificação das relações. Significando isto que não apenas entendemos ser uma prerrogativa de qualquer universidade escolher os companheiros de viagem, os parceiros da cooperação, como há vantagens em que diferentes parceiros influenciem o entendimento sobre a universidade e o trabalho nas universidades. Como diz Carlos Pimenta "Por muito completa que seja uma universidade, (...) com especialistas em múltiplas áreas do saber, seria de um provincianismo castrador admitir-se que sozinha teria forças suficientes (...) para abarcar a grande diversidade de possibilidades de cooperação". (10, pg. 40)

Também não ignoramos as condições em que a cooperação entre os países desenvolvidos e os países em desenvolvimento se tem feito. As reservas, desconfianças e mal-estar que tem motivado. Partilhamos da opinião do pró-reitor da Universidade do Porto para a Cooperação com África quando sustenta que “(...) é urgente banir a concepção de que nós cooperamos com os PALOP para os ajudar" e que uma cooperação séria, produtiva, com efeitos multiplicadores, supõe um interesse mútuo, um interesse institucional das partes envolvidas. $(10$, pg. 38$)$

A cooperação não se fará sem um suporte institucional. Mas, acreditamos numa coisa. Diz-nos a experiência, que resultará vantajoso para a cooperação que esta possa basear-se num conhecimento sólido, numa estreita ligação entre os cooperantes. Sem o que continuará, porventura, a fazer-se, mas não com os mesmos resultados. Há companheiros nossos de outros países, pessoas que temos em elevada consideração, que falam, a propósito das relações universitárias entre países mais e menos desenvolvidos, em fortalecimento da ideologia do "internacionalismo científico". (4) Segundo esta perspectiva, as nações seriam "avaliadas em termos de ascendência e declínio, proeminência ou inferioridade, independência ou dependência científica". Assim, a ciência constituiria para muitos estados um meio de assegurar prestígio e estatuto internacional. No que constituiria uma subtil mas manifesta forma de imperialismo.

(ibidem, op. cit)

Neste contexto, muitos países do chamado "terceiro mundo" seriam induzidos a seguir os modelos dos países desenvolvidos. O que relegaria para um plano secundário outros problemas mais relevantes, "desencorajando a escolha de agendas e tópicos mais úteis e mais fortemente vinculados ao contexto e à problemática de cada país". (ibidem, op. cit) Conhecemos o problema, e também o contexto em que estas afirmações são produzidas. Julgamos não ser essa, no entanto, a nossa forma de estar neste relacionamento com a Universidade Pedagógica. Outros melhor do que nós, no entanto, avaliarão essa participação.

Portugal não é aliás, como é sabido, um exemplo acabado de país desenvolvido, embora a sua história e cultura tenham uma importância ao nível da de outros grandes estados e povos europeus. Não vamos discutir a "ideologia" na cooperação universitária. As coisas são como são e os países que participam em programas de cooperação conhecem hoje bem as circunstâncias em que ela se faz, a partir de mil e um exemplos concretos.

Todavia, assim como não há "países em desenvolvimento", em abstracto, também não há "países desenvolvidos", no abstracto. Significando isto que os estados não têm necessariamente um mesmo entendimento e prática da cooperação. E, também, nem só dos estados vive a cooperação. Julgamos mesmo que nas relações de cooperação com os novos estados africanos, ex-colónias portuguesas, não será difícil encontrar exemplos de envolvimentos diferentes, de diferentes atitudes no processo de cooperação.

Não devemos por isso entender, apenas, o intercâmbio científico e ou universitário como um instrumento de "expansão cultural, penetração pacífica ou propaganda política”. (4) 
O acesso aos mercados, à tecnologia, ao saber, à excelência científica, a integração em redes científicas e universitárias internacionais devem assumir as formas que cada estado e cada povo entenderem ser as desejáveis.

Importante é que os países em desenvolvimento, ou do Sul, se se quiser, não fiquem isolados. E esse isolamento só terminará quando os problemas e realidades do sul fizerem parte da agenda internacional, voltarem a ocupar um lugar central nos esforços de cooperação internacional. (2) A globalização, a internacionalização, a criação de blocos económicos ou culturais, a pretexto de uma ideia ou de uma língua, são hoje uma realidade. Como dizia o Presidente do Brasil, Fernando Henrique Cardoso, na cerimónia de outorga do título de Doutor Honoris Causa pela Universidade do Porto: "Já não se trata apenas do Homem, sujeito individual, mas da Humanidade, sujeito colectivo, medida da própria sobrevivência de qualquer civilização ou cultura". (2, pg. 59) O que cada um de nós faz está a afectar os outros. Por isso, entenda-se da forma que se quiser isto, não podemos mais viver isolados. É importante desenvolver estratégias nacionais, regionais e globais, sem confrontações estéreis, de acordo com os interesses de todos e de cada um, isto é, de acordo com os interesses da Humanidade, de cada região, de cada estado, de cada povo.

Portugal é um exemplo, ainda actual, de quanto custa um isolamento, de 50 anos, do resto do mundo. A todos os níveis. Num percurso a não repetir, pelas implicações que tem sobre o empobrecimento de um povo, de uma cultura, e de uma história.

\section{A COOPERAÇÃO EM EDUCAÇÃO FÍSICA E DESPORTO}

Expusemos já, em algumas ideias, a nossa forma de estar na cooperação.

Permitam-nos agora, e não nos julguem mal por isso, - até porque Portugal também não é um país desenvolvido - que explicitemos o que, em nosso entendimento, deverá orientar a cooperação por parte de Moçambique. Que concretizemos algumas ideias na área a que estamos ligados.

A cooperação em Educação Física e Desporto deverse-á fazer, em nossa opinião, na observância de dois aspectos essenciais:

1) Ela deverá ser, antes de mais, determinada pelos interesses de Moçambique em áreas tidas como prioritárias, a partir de um quadro muito específico de identificação de problemas, próprios da realidade moçambicana.

2) Complementarmente, não deverá desvalorizar uma orientação que, partindo da identificação de problemas com actualidade nos países desenvolvidos, procure perspectivar mecanismos de intervenção que possam justificar-se em países em desenvolvimento, num quadro evolutivo previsível. Determinando a médio/ longo prazo alteração de orientações nas políticas de intervenção.

Sem esta perspectiva, evidentemente, ficará mais fragilizada a possibilidade de os moçambicanos, eles próprios, começarem a definir o modo de resposta às questões postas pelo desenvolvimento. Limitando, assim, as possibilidades de diminuir a sua dependência de terceiros.

Da primeira não trataremos aqui hoje. Outros, melhor do que nós, o poderão fazer e já o fizeram. Deixemos, então, os problemas concretos de Moçambique e vejamos o que mobiliza o interesse dos países com maior desenvolvimento científico e tecnológico, e socialmente mais avançados.

A generalização da prática vem-se constituindo como uma das bandeiras do Desporto e da Educação Física. No que corresponde a um esforço de democratização da participação na actividade física de todos os grupos sociais - mulheres e homens, novos e velhos, deficientes e grupos mais desfavorecidos; numa tentativa de promoção do direito efectivo dos cidadãos à prática de actividades físicas e desportivas. (7)

Neste contexto, o desporto de rendimento e de alto rendimento, tradicionalmente com larga aceitação, têm visto atenuada a sua importância junto dos órgãos do poder, que transferem as medidas e incentivos de apoio à prática para grupos populacionais mais numerosos. É assim que a saúde e o bem-estar surgem estrategicamente a referenciar os mais importantes programas de intervenção. 
A saúde é, cada vez mais, uma prioridade nos países desenvolvidos. Se é hoje crescente o sedentarismo nesses países, o próximo século, com o avanço nas tecnologias da informação, acentuará a pressão para a sedentarização. (8)

Alguns grupos constituem hoje alvo prioritário da incidência de medidas e das políticas de saúde, educacional e de segurança social: os idosos, e as crianças e jovens.

As conferências internacionais que discutem a investigação da actividade física na terceira idade vêm concluindo pela necessidade de atenuar os impactos negativos da redução da actividade física com o envelhecimento, exigindo a adopção de medidas efectivas em matéria de política social e de saúde, por parte dos governos nacionais e das autoridades internacionais. (6)

A Europa, em particular, - com a população mais idosa do mundo - começa a olhar este problema com cuidados especiais. Em 1988, - os dados são do Eurostat - nos países da Europa Ocidental cerca de $1 / 5$ da população tinha mais de 60 anos, esperando-se que no virar do século, por cada indivíduo com idade até aos 15 anos haja 9 com idade superior a 65 anos. (5)

$\mathrm{O}$ aumento da esperança de vida e o consequente envelhecimento das populações agravará, de forma drástica, os problemas já existentes com a saúde, a segurança social e o bem-estar das populações idosas, a menos que as autoridades competentes em matéria de políticas de saúde e de segurança social, juntamente com as instituições científicas e universitárias convirjam no estudo dos problemas e na adopção de medidas tendentes a atenuar estes efeitos. (5)

Num outro plano, mas ainda na saúde, sabe-se que a actividade física influencia positivamente o estatuto de saúde dos adultos. Tem-se, por este facto, procurado estimular junto destes estilos de vida activos. O que estará longe de ser conseguido, a julgar pelos graus de adesão à prática regular de actividades físicas.

Tem por isso crescido a convicção, junto de profissionais de educação física e de saúde, de que o incremento da actividade física na criança poderá influenciar a diminuição do sedentarismo nas futuras gerações adultas. (8)
Nesta circunstância, a escola está cada vez mais no centro das preocupações com a saúde. De facto, as crianças e jovens passam obrigatoriamente pela escola e participam em aulas de Educação Física. É nesta medida que se tem procurado compreender qual pode ser o contributo da escola na promoção da saúde?

Os estudos realizados têm convergido na realização de um consenso: mais do que promover hipotéticos benefícios a curto prazo, torna-se importante fazer educação para a saúde, isto é, aumentar o envolvimento das crianças na prática regular de actividades físicas, promover estilos de vida activos. Mas a escola, sendo parte maior de uma estratégia, não pode por si só resolver os problemas. $\mathrm{O}$ aumento da participação de crianças e adolescentes em actividades regulares, deverá ser conseguido também, através de um maior envolvimento em actividades extra-curriculares e na comunidade. Pensando ainda na criança é importante não esquecer o seu desenvolvimento motor e corporal. Neste sentido, os países industrializados, procurando corresponder às necessidades de movimento que a criança não encontra na sua vida quotidiana normal, confrontam-na cada vez mais cedo, com actividades motoras na escola. A Educação Física é, cada vez mais, parte das estratégias educativas logo a partir dos jardins de infância. (8) A Educação Física e o Desporto para deficientes vêm merecendo uma atenção crescente na comunidade internacional. Disso é prova o aumento da importância que estados e organizações não governamentais lhe vêm dedicando, a exemplo do que acontece nos Jogos Paraolímpicos, que, nos últimos anos, sob a égide do Comité Olímpico Internacional e do Comité Paraolímpico, vêm assumindo uma dimensão crescente.

Este um domínio de intervenção, que, por razões bem conhecidas, interessará - como vem aliás interessando, já que constitui um aspecto muito particular da nossa cooperação - a países como Moçambique e Portugal.

É preciso mobilizar a sociedade e criar medidas de apoio à reintegração social dos deficientes. Promover uma vida mais digna e com maior qualidade. $\mathrm{O}$ Desporto e a Educação Física constituirão, seguramente, instrumentos privilegiados duma estratégia de reintegração. 
A participação dos cidadãos na prática de actividades físicas é cada vez mais encorajada numa perspectiva cultural. A intervenção dos municípios na criação de equipamentos, formais e informais, é cada vez mais notória.

A cidade vai percebendo que não chega ter boas redes viárias, metropolitano, bons estádios, piscinas e palácios dos desportos. Uma cidade só será moderna com equipamentos sociais e espaços verdes para as práticas desportivas de lazer. E, sobretudo, com cidadãos a fazer desporto e actividade física. A questão ecológica está hoje na ordem do dia. A prática massiva e pouco regulamentada de alguns desportos tem constituído uma forte pressão sobre a natureza, afectando o ambiente e provocando-lhe desequilíbrios.

Isto ficou mais visível na sequência do impacto negativo que os J.O. de Albertville tiveram nas comunidades locais e na opinião pública internacional. Os J. O. de Lillehammer constituíram já um exemplo de um esforço centrado no controlo e preservação ambientais, envolvendo todas as partes interessadas: as organizações desportivas, o governo, as organizações ambientais, a indústria e as comunidades. (3)

A preservação do meio ambiente é, assim, uma das principais preocupações do desporto neste final de

\section{BIBLIOGRAFIA}

1. Bento J, Marques A. Uma língua, um espaço, uma comunidade de ciência do desporto. Prefácio. In: Bento J, Marques A (eds.) As Ciências do Desporto e a Prática Desportiva. (Vol. 1). Desporto na Escola. Desporto de Reeducação e Reabilitação. Porto: Faculdade de Ciências do Desporto e de Educação Física, Universidade do Porto, 1991:23-28.

2. Cardoso FH. Intervenção de Sua Excelência o Senhor Presidente da República Federativa do Brasil, Doutor Fernando Henrique Cardoso. Boletim da Universidade do Porto, 26-27, 1996: 56-59.

3. Da Costa LP. Desporto e natureza: tendências globais e novos significados. In: Da Costa L (ed.) Environment and Sport. An International Overview. Porto: Faculdade de Ciências do Desporto e de Educação Física, Universidade do Porto, 1997:61-76.

4. Junior AF. Envelhecimento populacional, atividade física e promoção da saúde. In: Marques A, Prista A, Junior AF (eds) Educação Física: Contexto e Inovação. Porto: Faculdade de Ciências do Desporto e de Educação Física, Universidade do Porto, Faculdade de Ciências da Educação Física e Desporto, Universidade Pedagógica de Moçambique, 1997: 35-45.

5. Marques A. Discurso de abertura da $1^{\text {a }}$ Conferência do EGREPA. In: Marques A, Gaya A, Constantino J. (eds.) século. Tanto a preservação do meio natural, como os critérios que definem as áreas construídas começam a ser cuidadosamente pensados. Temos orgulho em ter editado na nossa Faculdade, com a colaboração de especialistas internacionais, um dos mais importantes contributos para este problema: o livro, "Meio Ambiente e Desporto. Uma perspectiva Internacional" patrocinado, entre outros, pelo Comité Olímpico Internacional, pelos Comités Olímpicos de Lillehammer 1994 e Sidney 2000 e pela ONU, Organização das Nações Unidas.

\section{Sr. Reitor, Srs Ministros, dignissímas autoridades.}

Longo vai o nosso tempo e mal entrámos no tema. Tentando corresponder às motivações que terão presidido à atribuição da distinção com que me honram, procurei discorrer à volta de alguns aspectos que considero significantes.

Espero não os ter maçado com um discurso desinteressante.

Se o consegui não sei. Sei, isso sim, que esta distinção representará no futuro, mais do que agora, uma exigência elevada relativamente ao que se espera da minha Universidade, da minha Faculdade, e particularmente de mim.

No que me diz respeito, tudo farei para corresponder.

Physical Activity and Health in the Elderly. Proceedings of the 1st Conference of EGREPA. Porto: University of Porto Faculty of Sport Sciences and Physical Education, European Group for Research into Elderly and Physical Activity, Municipality of Oeiras, 1994:15-16.

6. Marques A, Vogelaere P. Physical Activity and Health in the Elderly. Conclusions of the 1st Conference of EGREPA. In: Marques A, Gaya A, Constantino J. (eds.) Physical Activity and Health in the Elderly. Proceedings of the 1st Conference of EGREPA. Porto: University of Porto - Faculty of Sport Sciences and Physical Education, European Group for Research into Elderly and Physical Activity, Municipality of Oeiras, 1994: 537-538.

7. Marques A. Repensar o Desporto. Horizonte 75, 1997: 3-10. 8. Marques A. Actividade Física e saúde. A perspectiva pedagógica. In: Armstrong N, Constantino JM, Piéron M, Marques AT, Dinis JA, Telama R, Pereira, JG A Educação para a saúde. O papel da Educação Física na promoção de estilos de vida saudáveis. Lisboa: Omniserviços/SPEF, 1998: 83-107. 9. Melo F. Órfãos de pai vivo. Visão 221, 1997:84-87.

10. Pimenta C. Cooperação: das evangelizações às corruptelas, um espaço de respeito mútuo. Boletim da Universidade do Porto 29/30, 1996:36-41. 